\title{
ADOLESCENT RESPONSE ON MENARCHE: A SCOPING REVIEW
}

\author{
Nahdiyatul Mukaromah, Ismarwati
}

Universitas ‘Aisyiyah Yogyakarta

\begin{abstract}
Background: Menarche (first menstrual period) is a sign of physical maturity in adolescent girls, which has an impact in the future, both from a psychological and socio-cultural perspective on adolescents. Menarche provides different responses and emotions to adolescent; this is due to differences in preparation for dealing with menarche. Scoping review aims to overview the menarche acceptance among adolescent.

Subjects and Method: This was a scoping review study using the Arksey \& O'Malley framework with 5 stages, including: identifying scoping review questions, identifying relevant articles using databased including PubMed, ScienceDirect, and EBSCO. This study using gray literature, selecting relevant articles using inclusion and exclusion criteria, mapping data charting and compiling, summarizing and producing a review report.

Results: There were 6 articles selected using the Hawker assessment checklist tools. Articles obtained were using qualitative methods. The article selected in this study were based on the methodology, year of publication, and the participants used in the article. Two major themes that emerged as a result of the scoping review were knowledge and attitude.

Conclusion: The acceptance of menarche among adolescents will differ depending on the information and support environment for adolescents. The acceptance of menarche in adolescents was still need an attention from health workers, families, and teachers. The provision of pre-menarche health education before adolescent reach menarche is important. So that adolescents are better prepared to gain good experiences and perceptions.
\end{abstract}

Keywords: acceptance, menarche, adolescence, scoping review

Correspondence:

Nahdiyatul Mukaromah. Universitas 'Aisyiyah Yogyakarta. Jl. Siliwangi, Yogyakarta, Indonesia. Email: nadianad996@gmail.com. Mobile: 085880451711 